\title{
Thoracic duct embolization via chest tube for a patient with postoperative traumatic chylothorax
}

\author{
Erin Williams, MD \\ Nader Hanna, MBBS \\ Ben Mussari, MD \\ Wiley Chung, MD
}

Accepted Nov. 30, 2020

\section{Correspondence to: \\ E. Williams \\ Department of Surgery \\ Queen's University \\ 76 Stuart St \\ Kingston ON K7L 2V7 \\ 17els1@queensu.ca}

Cite as: Can J Surg 2021 December 1; 64(6). doi: $10.1503 /$ cjs.022119

\section{SUMmARY}

We present the case of a 53-year-old man who experienced a postoperative chyle leak after minimally invasive esophagectomy with mass ligation of the thoracic duct; conservative management failed. Interventional radiology was unsuccessful initially in accessing the cisterna chyli with conventional methods, yet ethiodized oil was noted at the tip of his right chest tube. The chest tube and its tract were used as an avenue to access the thoracic duct and successfully facilitate its embolization.

hyle leak and chylothorax is a well-described complication in thoracic surgery. ${ }^{1,2}$ Lymphangiography has been used to identify the location of the injury, followed by thoracic duct embolization (TDE), typically with coils and glue via the cisterna chyli. ${ }^{3}$ This has been suggested as a minimally invasive and effective option thought to decrease the mortality and morbidity associated with surgical re-exploration and ligation. ${ }^{3}$ Access to the cisterna chyli is typically gained after lymphangiography through a transabdominal, transhepatic approach with a 25 - or 26-gauge needle. ${ }^{4}$ An alternative approach has been described by Guerva and colleagues ${ }^{4}$ whereby retrograde access to the thoracic duct is obtained at its insertion point into the left subclavian vein under ultrasonographic guidance in instances in which the cisterna chyli cannot be identified on the lymphangiogram.

We present a case of TDE in which the cisterna chyli could not be identified on intranodal lymphangiograms. Retrograde access via the left subclavian vein was also unsuccessful in localizing the entry point of the thoracic duct. One of the patient's existing chest tubes was then used to access the lymphatic system.

\section{Case report}

A 53-year-old man presented to the thoracic surgery clinic with a diagnosis of adenocarcinoma of the esophagus confirmed on pathologic examination. $\mathrm{He}$ underwent neoadjuvant chemoradiation, with an excellent response. Laparoscopic gastric devascularization was performed as part of gastric conduit conditioning 2 weeks before he underwent minimally invasive Ivor Lewis esophagectomy. Intraoperatively, extensive adhesions were noted on mobilization of the intrathoracic esophagus, and supradiaphragmatic mass ligation of the thoracic duct was performed. The soft tissue intervening between the esophagus, azygos vein, descending thoracic aorta and vertebral column deep to the operative field was ligated distally with a large titanium metal clip (Weck Horizon, Teleflex) just above the diaphragm. The intervening tissue included in the clip contained the thoracic duct and plexus of lacteals. A large proximal clip was also applied $3 \mathrm{~cm}$ superiorly. Posterior-apical and anterior-basal 28-French chest tubes were inserted intraoperatively before closure.

On postoperative day 3 , the chest tube output was serous but remained at $1 \mathrm{~L}$ in 24 hours. Pleural fluid was negative for triglycerides. The output on 
postoperative day 4 was only $500 \mathrm{~mL}$ per 24 hours, with no residual pleural effusion on chest radiographs. Trickle feeds were started through the patient's jejunostomy tube. On postoperative day 5 , although the chest tube output remained low, it appeared milky and was confirmed to be chyle. Given that the chest tube output was less than less than $10 \mathrm{~mL} / \mathrm{kg} / \mathrm{d}$, it was felt that it would be reasonable to consider a trial of nonsurgical management. The patient was given nothing by mouth, and total parental nutrition was started. The chest tube output remained less than $500 \mathrm{~mL} / \mathrm{d}$.

On postoperative days $12-14$, the chest tube output increased to about $1.5 \mathrm{~L}$ per 24 hours, and the patient was offered right thoracotomy and repeat mass ligation of the thoracic duct. He was aware that a nonoperative approach could be unsuccessful and potentially worsen his immunosuppression, electrolyte abnormalities and malnutrition, but he declined repeat operative intervention owing to his complex underlying anxiety, preferring to exhaust all nonoperative options first.

Over the next week, octreotide was introduced subcutaneously at increasing dosages and frequency, which helped reduce the chest tube output to as low as $350 \mathrm{~mL}$ per 24 hours; however, the patient could not tolerate it, experiencing nausea, vomiting and new-onset headaches, and it was stopped. The chest tube output subsequently returned to as high as $2.5 \mathrm{~L}$ per 24 hours. The patient was then offered TDE and agreed to consider surgery if TDE was unsuccessful. Lymphangiography and TDE were performed on postoperative day 29. Lymphangiography was performed bilaterally by means of an intranodal injection technique with 25-gauge spinal needles for entry, and ethiodized oil was injected, which confirmed outflow via lymphatic channels (Figure 1).

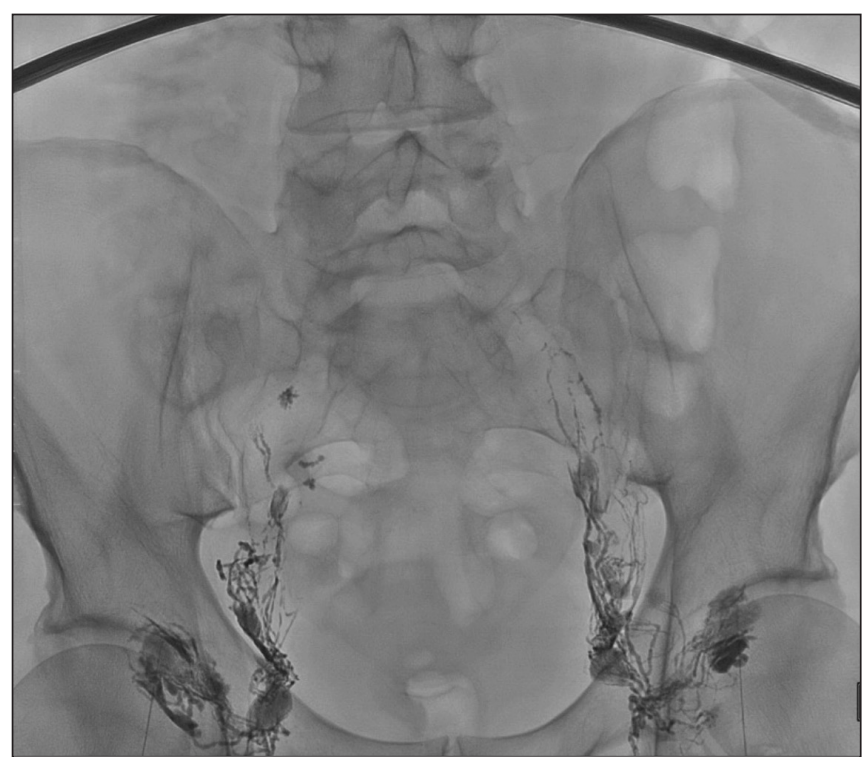

Fig. 1. Bilateral inguinal lymph node injection lymphangiogram showing opacification of bilateral pelvic lymphatic channels.
Despite injection of ethiodized oil, there was very little opacification of the retroperitoneal lymphatic channels, but ethiodized oil was noted at the tip of the right-sided chest tube situated in the posterior mediastinum as well as within the chest tube (Figure 2). After unsuccessful attempts at localizing the lymphatic channel/cisterna chyli percutaneously and through left arm venous access, the possibility of approaching the thoracic duct via the chest tube was discussed.

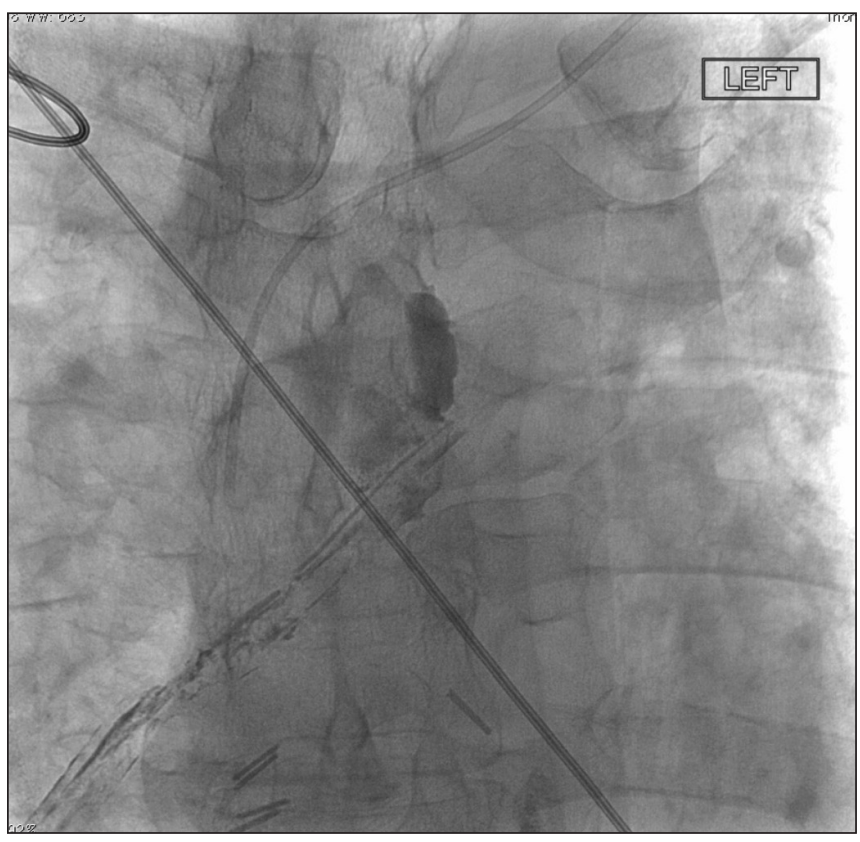

Fig. 2. Chest fluoroscopic image showing ethiodized oil in the mediastinum and within the right-sided chest tube.

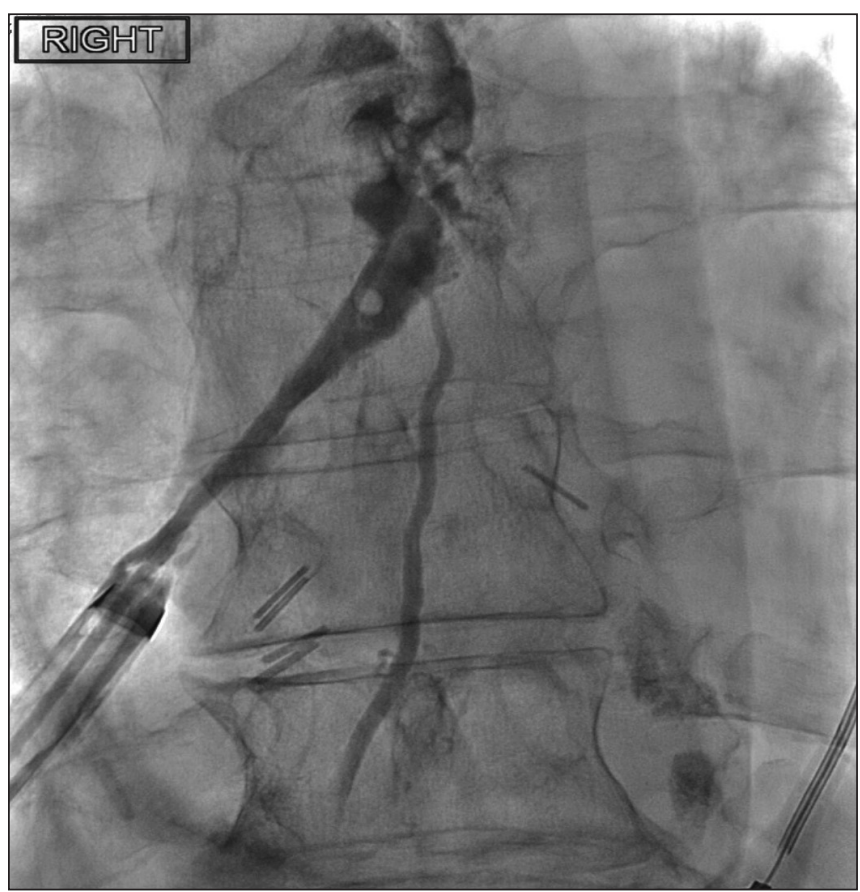

Fig. 3. Chest fluoroscopic image with contrast outlining an irregular cavity and filling of the thoracic duct at the lower margin. 
On postoperative day 32, fluoroscopy of the chest confirmed that ethiodized oil was still present at the tip of the right-sided chest tube in the posterior mediastinum. The chest tube was removed with the use of a stiff guide wire (Amplatz Super Stiff, Boston Scientific), and a long 18-French

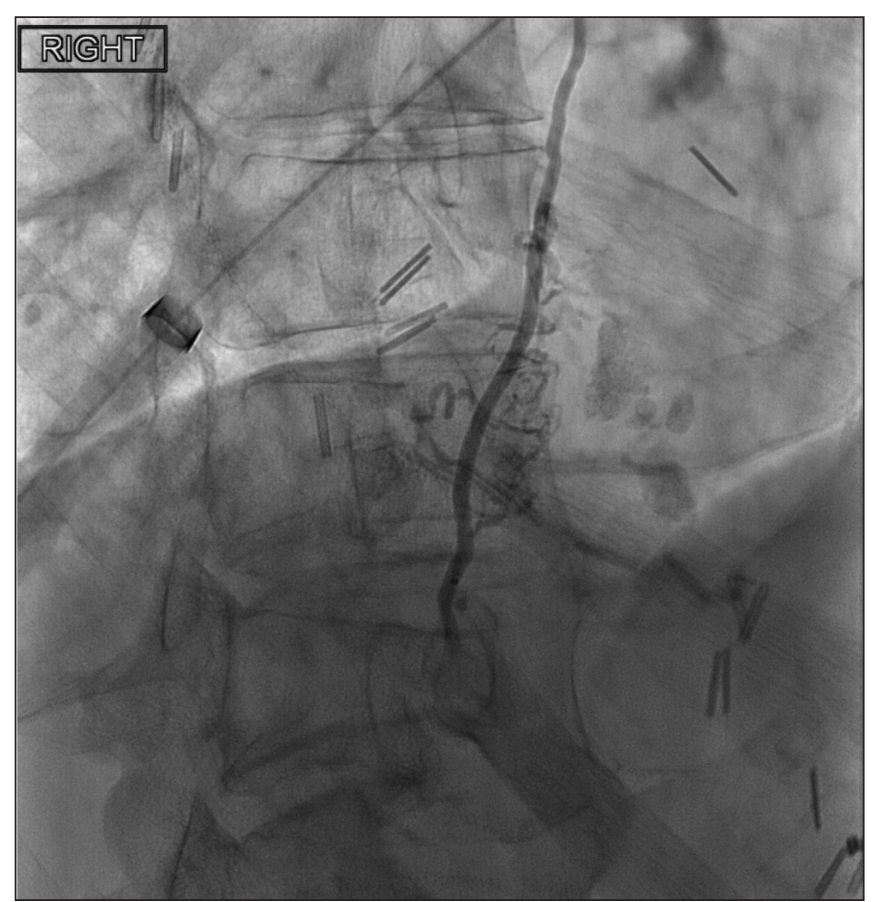

Fig. 4. Chest fluoroscopic image showing the thoracic duct selected with a microcatheter.

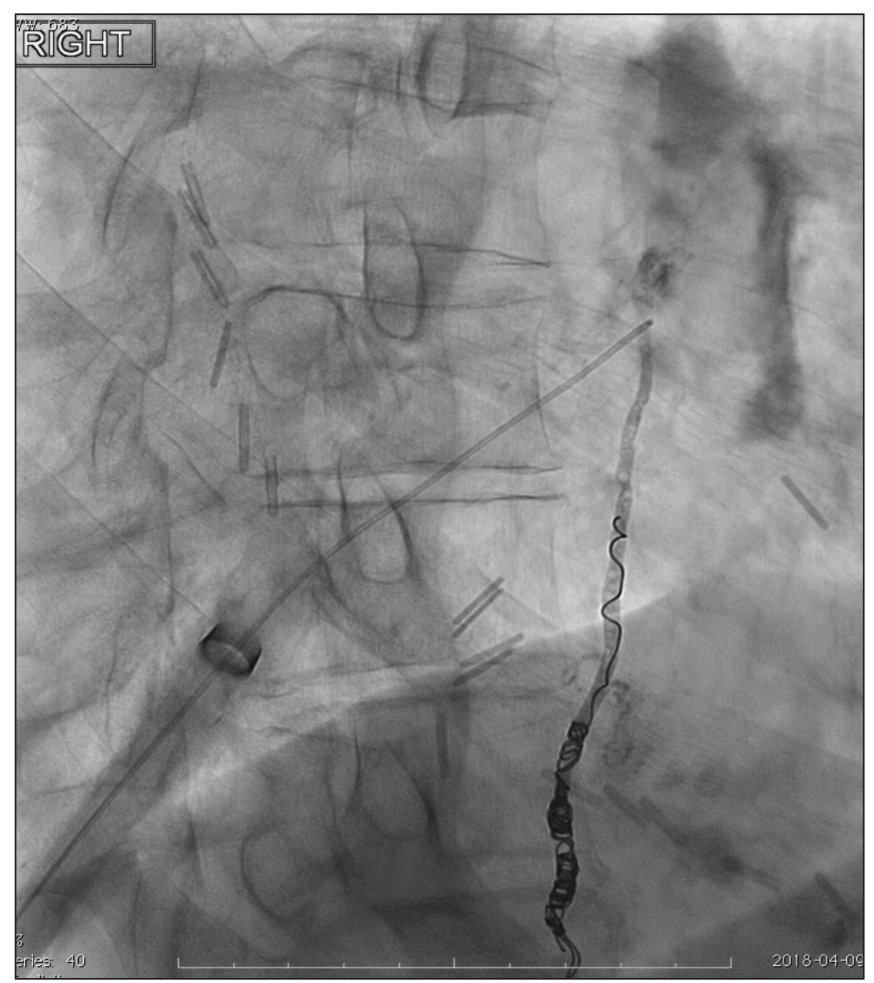

Fig. 5. Chest fluoroscopic image showing coil embolization of the thoracic duct. vascular sheath was inserted along the chest tube track to the posterior mediastinum. Contrast was injected with a 5 -French access catheter (Kumpe, Cook Medical) at the site of the ethiodized oil, which outlined an irregular cavity with filling of the thoracic duct at the lower margin (Figure 3).

With the use of an SOS Omni selective catheter (AngioDynamics) with the tip removed for acute angulation, the thoracic duct was eventually selected, and a Progreat microcatheter (Terumo Medical Corporation) was advanced into the upper abdomen where the duct appeared occluded (Figure 4). Multiple $3 \mathrm{~mm} \times 14 \mathrm{~cm} 0.018$-inch Nester coils were deployed distally via the microcatheter, followed by a mixture of glue and ethiodized oil (1:4 ratio) to the posterior mediational cavity, at the tip of the chest tube (Figure 5). A fibrin sheath related to the chest tube was noted extending to the chest wall, with no communication with the pleural space, and, therefore, a new chest tube was not inserted. An occlusive dressing was then applied.

After embolization, the chylous output stopped immediately. The patient recovered well, and his lymphocyte count started to improve. The right-sided chest tube was removed, his diet advanced gradually, and he was discharged home on postoperative day 41 .

\section{Discussion}

Chylothorax after surgery is estimated to occur in less than $0.5 \%$ of all general thoracic surgery cases and $3.9 \%$ of esophagectomy cases. ${ }^{5,6}$ Chylothorax can cause considerable morbidity, resulting in malnutrition, immunosuppression, sepsis, pulmonary complications, and fluid and electrolyte imbalances. ${ }^{7,8}$ Once chylothorax is diagnosed, output is assessed; if it is low, nonoperative management, including avoiding oral intake, nutritional support via total parenteral nutrition or medium-chain triglycerides, source control with a chest tube, and the use of somatostatin analogues (e.g., octreotide) to inhibit gastric secretions and chyle flow, is attempted for up to 2 weeks. ${ }^{1,2}$ Output is then quantified as high ( $>500 \mathrm{~mL} / \mathrm{d}$ or $>10 \mathrm{~mL} / \mathrm{kg}$ ) or low ( $\leq 500 \mathrm{~mL} / \mathrm{d}$ or $\leq 10 \mathrm{~mL} / \mathrm{kg}$ ); conservative management is successful in $25 \%-50 \%$ of cases overall. ${ }^{2}$ Because highoutput chylothorax is associated with high mortality rates, earlier operative management is indicated. In low-output chylothorax, the optimal management strategy is not definitive; nonoperative strategies can precipitate dehydration, malnutrition and major electrolyte abnormalities. ${ }^{1}$ General operative management strategies include mass ligation of the thoracic duct, parietal pleurectomy to achieve pleurodesis if the leak cannot be located and, for patients at high risk, pleuroperitoneal shunting. ${ }^{2}$

We do not know why initial intraoperative mass ligation of the thoracic duct was unsuccessful in our patient. Possible reasons include trauma to the thoracic duct wall at the level of ligation and incomplete mass ligation secondary to anatomic variants. ${ }^{9}$ The output of chylothorax was initially 
low and was managed nonoperatively. Once the output became high, surgical management was not an option because of patient preference. We attempted TDE when nonoperative management failed. Lymphangiography can be used to localize the thoracic duct injury, followed by TDE. Intranodal lymphangiography is replacing pedal lymphangiography, as it is less technically challenging and is associated with reduced morbidity and recovery time compared to the pedal approach. ${ }^{10}$ When the thoracic duct is not visualized, attempts can be made to access the duct retrograde via the left subclavian vein. ${ }^{4}$ Both procedures were unsuccessful in accessing the thoracic duct in this case.

Access to the lymphatic system via a posteriorly placed chest tube provided an alternative option in the present case. This approach may lower the risk of infection by avoiding the creation of multiple tracts and decreasing damage to important adjacent structures, and requires less time and fluoroscopy. It should be considered in patients whose anatomy is favourable if the tip of a chest tube is near a site of ethiodized oil extravasation in the posterior mediastinum.

Accessing the lymphatic system via a chest tube tract is an innovative approach for TDE. Future study is warranted regarding using chest tubes as an avenue to access the lymphatic system, potentially decreasing infection, damage to adjacent structures and the time involved in TDE.

Affiliation: From Queen's University, Kingston, Ont.

Competing interests: None declared.

Consent: For this type of study, formal consent is not required. Informed consent was obtained from the patient. Institutional ethics review board approval was not required.

Contributors: E. Williams and N. Hanna designed the study. B. Mussari and $W$. Chung acquired the data. All authors wrote the manuscript, which E. Williams, B. Mussari and W. Chung critically revised. All authors gave final approval of the article to be published.
Content licence: This is an Open Access article distributed in accordance with the terms of the Creative Commons Attribution (CC BYNC-ND 4.0) licence, which permits use, distribution and reproduction in any medium, provided that the original publication is properly cited, the use is noncommercial (i.e., research or educational use), and no modifications or adaptations are made. See: https://creativecommons. org/licenses/by-nc-nd/4.0/.

Funding: This study was not supported by any funding.

\section{References}

1. Grimminger PP, Goense L, Gockel I, et al. Diagnosis, assessment and management of surgical complications following esophagectomy. Ann N Y Acad Sci 2018;1434:254-73.

2. Fortin D, Inculet RI, Malthaner RA. The thoracic duct and chylothorax. In: Patterson GA, Griffith Pearson F, Cooper JD, et al., editors. Pearson's thoracic and esophageal surgery, 3rd ed. Vol. 1. Philadelphia: Churchill Livingstone Elsevier; 2008:1108-20.

3. Binkert CA, Yucel EK, Davison BD, et al. Percutaneous treatment of high-output chylothorax with embolization or needle disruption technique. 7 Vasc Interv Radiol 2005;16:1257-62.

4. Guevara CJ, Rialon KL, Ramaswamy RS, et al. Direct puncture retrograde thoracic duct access, lymphangiography, and embolization: feasibility and efficacy. 7 Vasc Interv Radiol 2016;27:1890-6.

5. Itkin M, Kucharczuk JC, Kwak A, et al. Nonoperative thoracic duct embolization for traumatic thoracic duct leak: experience in 109 patients. F Thorac Cardiovasc Surg 2010;139:584-9, discussion 589-90.

6. Kurklinsky AK, McEachen JC, Friese JL. Bilateral traumatic chylothorax treated by thoracic duct embolization: a rare treatment for an uncommon problem. Vasc Med 2011;16:284-7.

7. Allison S, Rainey M, Aarabi S, et al. Traumatic laceration of the cisterna chyli treated by lymphangiography and percutaneous embolization. Cardiovasc Intervent Radiol 2014;37:267-70.

8. Garcia RG, Rocha RD, Franceschini J, et al. Computed tomographyguided percutaneous thoracic duct sclero-embolization for persistent chylothorax. Innovations (Philia) 2016;11:291-4.

9. Hoeppner J, Hopt UT. Transabdominal mass ligation of the thoracic duct for the prevention of chylothorax following en bloc oesophagectomy. Eur 7 Cardiothorac Surg 2013;44:1134-6.

10. Nadolski GJ, Itkin M. Feasibility of ultrasound-guided intranodal lymphangiogram for thoracic duct embolization. 7 Vasc Interv Radiol 2012;23:613-6. 